\title{
Eficiência de formulações de ulvana em induzir resistência em Phaseolus vulgaris contra Colletotrichum lindemuthianum
}

\author{
Mateus B. de Freitas ${ }^{1}$, Cláudia C. Medugno ${ }^{2}$, Rafael F. Schons ${ }^{1} \&$ Marciel J. Stadnik $^{1}$ \\ ${ }^{1}$ Departamento de Fitotecnia, Universidade Federal de Santa Catarina, 88040-900, Florianópolis, SC, Brasil; ${ }^{2}$ Embrapa Meio \\ Ambiente, 13820-000, Jaguariúna, SP, Brasil
}

Autor para Correspondência: Marciel J. Stadnik, e-mail: stadnik@cca.ufsc.br

\begin{abstract}
RESUMO
O presente trabalho objetivou avaliar a eficácia da ulvana, um polissacarídeo proveniente de alga, em induzir resistência em Phaseolus vulgaris contra Colletotrichum lindemuthianum, quando formulada sozinha ou com caulinita, sílica amorfa ou atapulgita e armazenada por $0,4,8$ ou 12 meses. Após cada período de armazenamento, as formulações e água (controle) foram aplicadas à folhagem de plantas de feijão (cv. Uirapuru, estádio fenológico $\mathrm{V}_{4}$ ) aos 6 e 3 dias antes da inoculação com C. lindemuthianum. A severidade da antracnose foi estimada em intervalos de 2 dias, com o aparecimento dos primeiros sintomas até 13 dias após a inoculação. A partir dos dados de severidade calculou-se a Área Abaixo da Curva de Progresso da Doença (AACPD). A aplicação de ulvana (controle) ou de suas formulações com sílica amorfa ou caulinita, promoveu uma redução de cerca de $45 \%$ na severidade da antracnose. A eficiência da ulvana em controlar a antracnose foi mantida nas formulações com sílica amorfa ou caulinita, mas não naquela contendo atapulgita, durante o período de 12 meses.
\end{abstract}

Palavras-chave: Antracnose, atapulgita, caulinita, feijão, sílica amorfa, ulvana.

\section{ABSTRACT}

Effectiveness of formulas based on ulvan in inducing resistance in Phaseolus vulgaris against Colletotrichum lindemuthianum

The present work aimed to evaluate the effectiveness of ulvan, an algal polysaccharide, in inducing resistance of Phaseolus vulgaris against Colletotrichum lindemuthianum when formulated alone or with kaolinite, amorphous silica or attapulgite, and stored for $0,4,8$, or 12 months. Following each storage period, the formulations and a water control were applied to the foliage of bean plants (cv. Uirapuru, growth stage $\mathrm{V}_{4}$ ) at 6 days, and again at 3 days, before the foliage was inoculated with $C$. lindemuthianum. Anthracnose severity was estimated at intervals of 2 days, beginning when the first symptoms appeared and continuing until 13 days after inoculation. The severity data were used to calculate values for Area Under the Disease Progress Curve (AUDPC). The application of ulvan (control) or its formulations with amorphous silica or kaolinite reduced anthracnose severity by $45 \%$. The efficiency of ulvan in controlling anthracnose was maintained throughout 12 months of storage when it was formulated with amorphous silica or kaolinite, but not with attapulgite. Key words: Amorphous silica, anthracnose, attapulgite, common bean, kaolinite, ulvan.

A antracnose, causada pelo fungo Colletotrichum lindemuthianum (Sacc. \& Magnus) Scrib. é uma das doenças mais importantes da cultura do feijão (Phaseolus vulgaris L.) no mundo. Até o presente momento, a utilização de cultivares resistentes e a pulverização de fungicidas são as principais medidas recomendadas para o seu controle (Wordell \& Stadnik, 2008). Por outro lado, a exigência crescente dos consumidores por alimentos livres de agrotóxicos aliada ao aumento nos custos da produção e a ocorrência de patógenos resistentes, vem levando a necessidade de se utilizar métodos alternativos para o controle de doenças.

Atualmente, oligo e polissacarídeos algais vêm sendo estudados quanto a sua capacidade de atuar na regulação do crescimento e desenvolvimento de plantas e, na elicitação de seus mecanismos de defesa contra estresses bióticos e abióticos (Stadnik \& Paulert, 2008). Entre esses, o mais estudado é a laminarana (ou laminarina), que é um polímero de $\beta-1,3$ glucanos obtido de Laminaria digitata. A laminarana ativa múltiplas respostas de defesa em plantas contra patógenos. Na Europa e Estados Unidos encontra-se registrada e está disponível comercialmente em formulações líquidas (ex.: Vacciplant ${ }^{\circledR}$, Iodus ${ }^{\circledR}$ ), para controle de doenças de grandes culturas tais como trigo, cevada, arroz, videira, maçã e pêra (Elmer \& Reglinski, 2006; Renard-Merlier et al., 2007). Por exemplo, em videira e trigo, a pulverização de laminarana $\left(0,5\right.$ a $\left.1 \mathrm{~g} \mathrm{~L}^{-1}\right) 10$ dias antes da inoculação de Plasmopara viticola e Blumeria graminis é capaz de reduzir a severidade da doença em até 75\% (Aziz et al., 2003) e $60 \%$, respectivamente (Renard-Merlier et al., 2007).

Algas do gênero Ulva, conhecidas como alface do mar ("sea lettuce"), encontram-se amplamente distribuídas ao redor do mundo, porém, suas potencialidades têm sido pouco exploradas (Paulert et al., 2009). A partir de algas deste gênero, é extraído um heteropolissacarídeo solúvel em água (Cluzet et al., 2004; Paulert et al., 2009), que vem 
demonstrando potencial para o controle da antracnose do feijão (Paulert et al., 2009).

Paulert et al. (2009) identificaram o polissacarídeo de $U$. fasciata por RNM-1H e RNM-13C como unidades repetidas do ácido ulvanobiurônico-3-sulfato, denominado ulvana. Em condições de casa-de-vegetação, verificou-se que a aplicação foliar preventiva de ulvana em feijão (P. vulgaris) reduziu a severidade da antracnose (C. lindemuthianum) em 38\% (Paulert et al., 2009). Com isto e considerando que a ulvana não inibe o crescimento micelial e a germinação de conídios do fungo in vitro, sugeriu-se que o controle obtido foi resultado da indução de resistência da planta. De fato, Cluzet et al. (2004) monitoraram a expressão de 152 genes de Medicago truncatula (Gaertn.) após o tratamento com ulvana e em resposta à infecção de Colletotrichum trifolii (Bain.), causador da antracnose. O polissacarídeo eficientemente elicitou múltiplas respostas de defesa, tais como a biosíntese de fitoalexinas e de proteínas relacionadas à patogênese (PR-proteínas). Segundo estes autores, o polissacarídeo não apresenta fitotoxicidade, nem causa alteração do metabolismo primário da planta devido a sua aplicação.

Com o desenvolvimento ou identificação de moléculas bioativas, faz-se necessário, por vezes, o preparo de formulações contendo agentes que visem eliminar características indesejáveis ou mesmo melhorar sua atividade biológica (Medugno, 2007; Knowles, 2008).

Produtos fitossanitários naturais à base de algas marinhas são muitas vezes comercializados, inclusive no Brasil, como biofertilizantes ou bioestimulantes na forma de solução concentrada. Estes produtos têm em sua composição, além do ingrediente ativo (extrato ou polissacarídeos algais), outros nutrientes e compostos. Sua aplicação inclui: melhorar a germinação das sementes, o crescimento das raízes, a produção de flores, a frutificação e até mesmo, a resistência a doenças, geada e seca (Stadnik \& Paulert, 2008).

Dentre as demais formulações conhecidas, pode-se destacar a pó molhável (PM), que pode ser utilizada quando o ingrediente ativo pode ser moído a seco em moinhos mecânicos ou por moagem a ar (Knowles, 2008). A primeira etapa no desenvolvimento de uma formulação PM consiste na seleção de um diluente adequado e compatível com o ingrediente ativo. Além de sua função diluente, este componente pode ser quimicamente ativo, afetando o $\mathrm{pH}$ da solução, melhorando a suspensibilidade, prevenindo a compactação, imobilizando substâncias que poderiam afetar o ingrediente ativo e retendo umidade. Estas propriedades permitem a alteração do microambiente em torno do ingrediente ativo, melhorando o armazenamento, a manipulação e a aplicação do produto (Ward, 1984; Medugno, 2007). Um PM tem em sua composição, além do diluente e do ingrediente ativo, agentes surfactantes, que visam conferir molhabilidade e reduzir a sedimentação (Medugno, 2007).
Até o presente momento, não há relatos do desenvolvimento de formulações de PM de oligo e polissacarídeos algais. Assim, o presente trabalho objetivou avaliar o efeito de diferentes diluentes na eficiência da ulvana em induzir respostas de defesa em plantas de Phaseolus vulgaris contra o fungo Colletotrichum lindemuthianum.

Para tanto, foram realizados quatro experimentos, em condições de casa-de-vegetação, durante o período de um ano ( $0,4,8$ e 12 meses após o preparo das formulações), conduzidos consecutivamente nos meses de agosto e dezembro de 2008 e, abril e agosto de 2009.

O polissacarídeo ulvana foi obtido a partir da alga Ulva fasciata, conforme descrito por Paulert et al. (2009). Para isso, $100 \mathrm{~g}$ da alga seca foram autoclavados em um litro de água destilada durante duas horas a $110^{\circ} \mathrm{C}$. A solução aquosa obtida foi filtrada e em seguida realizou-se a precipitação do polissacarídeo com a adição de três volumes de etanol $\left(98^{\circ} \mathrm{GL}\right)$, seguido do resfriamento a $-20^{\circ} \mathrm{C}$ por 48 h. Então, os compostos precipitados foram coletados, secos a $45 \pm 5^{\circ} \mathrm{C}$ por $48 \mathrm{~h}$ até peso constante e mantidos a $5^{\circ} \mathrm{C}$, até o seu processamento e formulação.

Para o preparo das formulações foram utilizados os seguintes diluentes: sílica amorfa (Aerosil 200 ${ }^{\circledR}$, Degussa/ Evonik, Alemanha), composta basicamente por dióxido de silício $\left(\mathrm{SiO}_{2}\right)$, caulinita (Caulim Monte Pascoal ${ }^{\circledR}$, Monte Pascoal, Brasil), composta por óxido de alumínio $\left(\mathrm{Al}_{2} \mathrm{O}_{3}\right)$ e dióxido de silício $\left(\mathrm{SiO}_{2}\right)$ e atapulgita (Attagel 50 Engelhard $^{\circledR}$, BASF, Estados Unidos), constituída por óxido de magnésio $(\mathrm{MgO})$, óxido de alumínio $\left(\mathrm{Al}_{2} \mathrm{O}_{3}\right)$ e dióxido de silício $\left(\mathrm{SiO}_{2}\right)$.

O polissacarídeo foi moído junto com cada diluente em uma proporção de 1:1 (p/p; diluente: ulvana) em moinho de bolas (MA350, Marconi) até a obtenção de um pó fino (diâmetro médio de partículas $=29,4 \mu \mathrm{m}$ ). A limpeza do moinho, entre as moagens, foi realizada com a adição do próximo diluente a ser utilizado na moagem posterior. Em seguida, as formulações foram acondicionadas em frascos de polipropileno $(100 \mathrm{~mL})$ com tampa de rosca e armazenadas a $24 \pm 5^{\circ} \mathrm{C}$ e $60 \%$ de umidade relativa do ar. A avaliação do $\mathrm{pH}$ foi realizada aos 12 meses após o preparo dos tratamentos. As formulações de ulvana com a caulinita, a sílica amorfa e a atapulgita apresentaram $\mathrm{pH}$ de 7,6, 7,3 e 7,1, respectivamente, enquanto que o $\mathrm{pH}$ observado para a ulvana pura foi de 6,8 .

Plantas de feijão (Phaseolus vulgaris L. cv. Uirapuru) foram cultivadas em vasos plásticos (dois litros), contendo uma mistura de solo argiloso e composto orgânico (4:1; v/ v). As temperaturas de cultivo foram de $22 \pm 5^{\circ} \mathrm{C}, 30 \pm 6^{\circ} \mathrm{C}$, $18 \pm 6^{\circ} \mathrm{C}$ e $20 \pm 5^{\circ} \mathrm{C}$, para os tempos de $0,4,8$ e 12 meses após o preparo das formulações, respectivamente.

Ao emitirem o segundo trifólio completamente expandido (estádio fenológico $\mathrm{V}_{4}$ ), as plantas foram pulverizadas ( $3 \mathrm{~mL}$ por planta) com as suspensões das formulações, usando uma pistola de pintura (Grifo ${ }^{\circledR}$, Itália) acoplada a um compressor de ar (pressão de $25 \mathrm{lbf} / \mathrm{pol}^{2}$ ). As plantas foram pulverizadas duas vezes, aos 6 e 3 dias antes da inoculação, conforme descrito por Paulert et al. 
(2009). As formulações (50\% i.a.) foram aplicadas a 20 $\mathrm{mg} \mathrm{mL} \mathrm{m}^{-1}$. A pulverização de ulvana $\left(10 \mathrm{mg} \mathrm{mL}^{-1}\right)$ e água destilada serviram como testemunhas positiva e negativa, respectivamente.

Utilizou-se o isolado MANE 001-03 da raça fisiológica 73 de Colletotrichum lindemuthianum (Loffaguen et al., 2005). O inóculo foi obtido após o crescimento do fungo por 15 dias sobre vagens de feijão, conforme metodologia descrita por Talamini et al. (2004). As plantas foram aspergidas com uma suspensão de $3 \times 10^{6}$ conídios por $\mathrm{mL}$ quando apresentaram o terceiro trifólio completamente expandido. As plantas foram mantidas em câmara úmida (umidade relativa $>90 \%$ ) no escuro por 48 h. Findo este período, as plantas foram transferidas novamente para bancada em casa-de-vegetação, onde permaneceram até a avaliação dos sintomas da antracnose. A severidade da antracnose foi avaliada a cada dois dias a partir do aparecimento dos primeiros sintomas até 13 dias após a inoculação (d.a.i.), totalizando quatro avaliações. Para tanto, foi utilizada a escala de Rava et al. (1993) com notas para a porcentagem de área foliar lesionada que variam de 1 (ausência de sintomas) a 9 (maioria das plantas mortas). A partir das notas, foi calculada a Área Abaixo da
Curva de Progresso da Doença (AACPD), utilizando-se a seguinte fórmula: $\mathrm{AACPD}=[((\mathrm{y} 1+\mathrm{y} 2) / 2) *(\mathrm{t} 2-\mathrm{t} 1))]$, onde y1 e y2 são duas avaliações consecutivas de severidade realizadas nos tempos t1 e t2, respectivamente (Araújo et al., 2010).

Os experimentos foram conduzidos em delineamento experimental completamente casualizado, com cinco repetições. Cada repetição foi constituída de um vaso com três plantas. A severidade da parcela foi obtida através da média aritmética da severidade das três plantas constituintes da repetição.

A severidade da antracnose avaliada 13 dias após a inoculação no primeiro e segundo trifólios de plantas testemunhas, atingiu, em média, nota 5. Estas plantas apresentavam lesões necróticas visíveis em ambas as faces da folha atingindo até 3\% das nervuras (Figura 1). A pulverização de ulvana ou das formulações do polissacarídeo com a sílica amorfa ou caulinita, reduziu a severidade aos 13 d.a.i., em média, em 43, 50 e 47\%, respectivamente. AAACPD nas plantas testemunhas foi em média 44. A pulverização com ulvana e com as formulações do polissacarídeo com a sílica amorfa e caulinita reduziu a AACPD em média, em 44, 48 e 46\%, respectivamente.
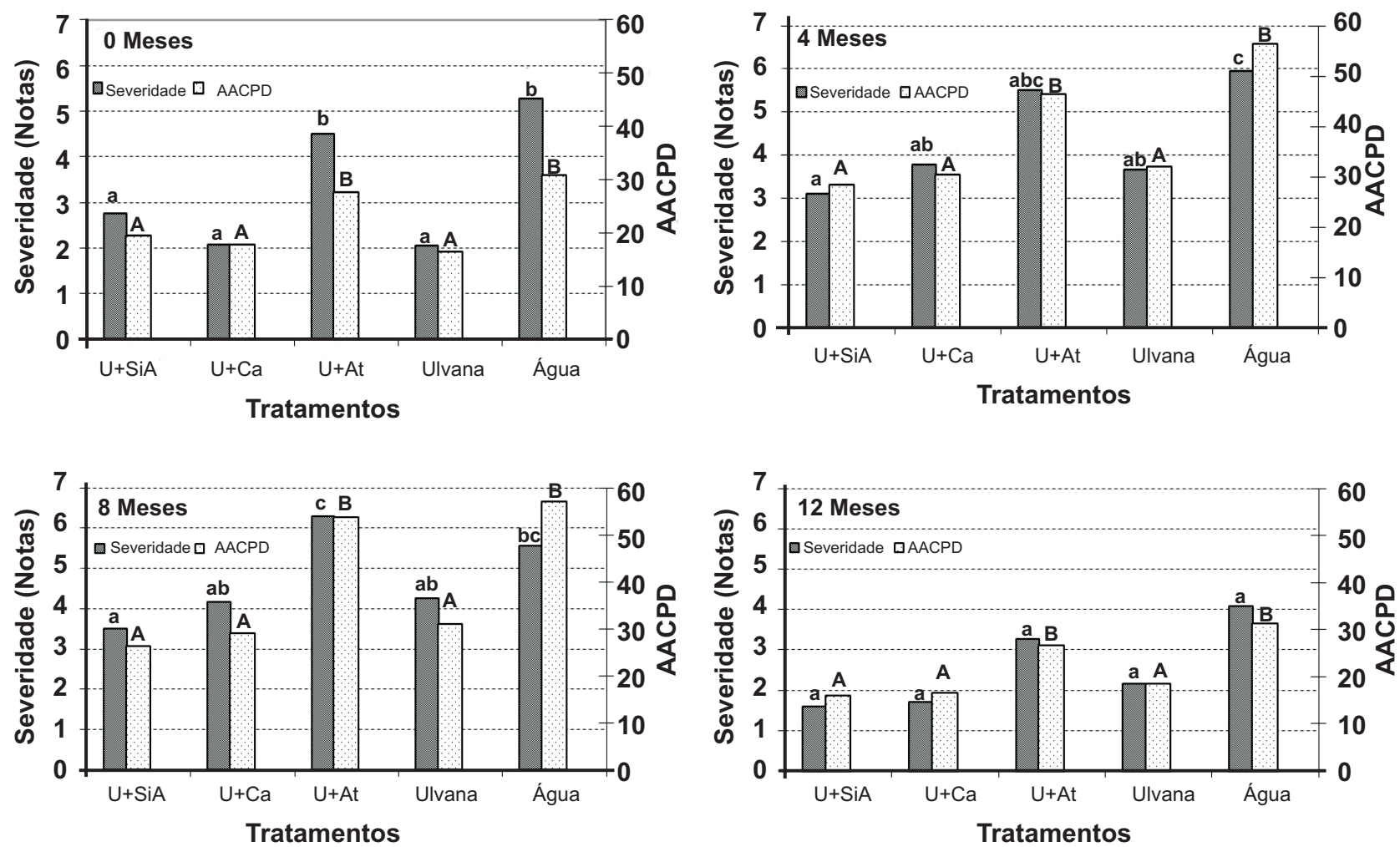

FIGURA 1 - Severidade da antracnose aos 13 d.a.i e Área Abaixo da Curva de Progresso da Doença (AACPD) avaliadas no primeiro e segundo trifólios de plantas de Phaseolus vulgaris cv. IPR Uirapuru pulverizadas com ulvana e as combinações de ulvana com os inertes caulinita $(\mathrm{U}+\mathrm{Ca})$, sílica amorfa $(\mathrm{U}+\mathrm{SiA})$ e atapulgita $(\mathrm{U}+\mathrm{At})$ (concentração final de ulvana $\left.=10 \mathrm{mg} \mathrm{mL}^{-1}\right)$, avaliadas aos $0,4,8$ e $12 \mathrm{meses}$ após o preparo das formulações. Letras minúsculas para a severidade e maiúsculas para a AACPD indicam diferença significativa ao nível de 5\% de significância pelo Teste de Tukey. 
Na última avaliação (agosto de 2009; 12 meses após o preparo das formulações), o efeito dos tratamentos com ulvana ou das formulações do polissacarídeo com a sílica amorfa ou caulinita foi significativo somente para a ACPD (Figura 1). A pulverização da formulação de ulvana com a atapulgita não reduziu significativamente a severidade aos 13 d.a.i e a AACPD, em nenhum dos momentos avaliados.

No presente trabalho, observou-se que a pulverização tanto de ulvana pura (testemunha positiva) quanto formulada com os diluentes sílica amorfa e caulinita, promoveu redução significativa (45\%) na severidade da antracnose (Figura 1) em plantas de $P$. vulgaris cv. IPR Uirapuru. Resultados semelhantes foram obtidos por Paulert et al. (2009), que relataram uma redução de $38 \%$ na severidade da antracnose em plantas de $P$. vulgaris previamente tratadas com ulvana. Considerando que a ulvana não possui efeito antifúngico e que pode elicitar respostas de defesa tanto local quanto sistemicamente em plantas (Cluzet et al., 2004; Paulert et al., 2009), pode-se atribuir a redução da doença a mecanismos de defesa induzidos pelo polissacarídeo.

A severidade final da antracnose e a AACPD foram afetadas de maneira semelhante pelas formulações de ulvana com a sílica amorfa ou caulinita durante os quatro períodos avaliados, especialmente nos três primeiros onde a intensidade de doença foi similar. No entanto, em agosto de 2009 (12 meses após o preparo das formulações) somente foi possível detectar diferença estatística quando se analisou a AACPD (Figura 1). Duas hipóteses podem ser levantadas para a explicação desses resultados: 1) A escala de notas de Rava et al. (1993) não seria suficientemente sensível para a detecção de pequenas variações na severidade, principalmente quando seus níveis são baixos. Como pode ser observado na Figura 1, a nota média máxima obtida foi 4, para plantas testemunhas, enquanto que, a nota média dos demais tratamentos foi 2 . Ambas as notas representam a mesma porcentagem de área foliar afetada (1\%). Ou ainda, 2) o nível de resistência induzido não foi significativo frente à testemunha que teve uma baixa severidade (Figura 1). Tem-se observado que os efeitos de indutores de resistência são dificultados em limites de doenças inferiores e superiores. Por exemplo, o priming induzido pela aplicação de sacarina em plantas de cevada contra Rhynchosporium secalis foi significativo somente sob alta pressão de inóculo $\left(5 \times 10^{5}\right.$ esporos por mL) (Walters et al., 2008). Por outro lado, a redução na incidência da murcha bacteriana em plantas de tomate pela aplicação de Acibenzolar-S-metil foi significativa, somente sob baixas concentrações de Ralstonia solanacearum $\left(10^{5} \mathrm{ou}\right.$ $10^{6}$ unidades formadoras de colônia por $\mathrm{mL}$ ) (Pradhanang et al., 2005).

Os diluentes caulinita e sílica amorfa não influenciaram a eficiência da ulvana em elicitar respostas de defesa em plantas de $P$. vulgaris contra $C$. lindemuthianum, durante o período de um ano (Figura 1). Estes diluentes são quimicamente estáveis e vêm sendo amplamente utilizados em cosméticos, alimentos, fertilizantes e pesticidas (Murray, 2007). Sabe-se que o silício está fortemente ligado nas partículas de argilas, não sendo liberado em soluções aquosas (Carroll \& Starkey, 1971), ao menos em níveis que possam ter efeito sobre doenças foliares.

O diluente atapulgita reduziu em todos os momentos avaliados a eficiência do polissacarídeo ulvana em elicitar respostas de defesa em plantas de $P$. vulgaris contra o fungo $C$. lindemuthianum (Figura 1). Considerando que o diluente pode interagir com o ingrediente ativo (Ward, 1984; Medugno, 2007; Knowles, 2008), pode-se sugerir que o polissacarídeo tenha sido adsorvido pela argila. Sabe-se que a ulvana pode formar agregados com a montmorilonita, através da formação de pontes de hidrogênio com os grupos hidroxilas da argila (Laza et al., 2007). A montmorilonita (fórmula empírica: $\left.(\mathrm{Na}, \mathrm{Ca})_{0,3}(\mathrm{Al}, \mathrm{Mg})_{2} \mathrm{Si}_{4} \mathrm{O}_{10}(\mathrm{OH})_{2} \cdot \mathrm{nH}_{2} \mathrm{O}\right)$ possui composição químico-física semelhante a atapulgita. Ambas as argilas apresentam fortes propriedades adsorventes (Ward, 1984). Durante o preparo dos tratamentos para a aplicação, observou-se que a formulação contendo atapulgita apresentou uma maior dificuldade de dissolução e formou aglomerados de partículas.

A ulvana não formou aglomerados de partículas com a caulinita (argila), como aqueles observados com a atapulgita. Isto pode ser explicado pela estrutura química destas argilas. A caulinita é estruturada em duas camadas, uma de tetraedros de óxido de silício e outra de octaedros de óxido de alumínio. Ao contrário da caulinita, a atapulgita não é estruturada em camadas e sim em forma de cadeia de tetraedros de óxido de silício ligados por octaedros de oxigênio e hidroxilas contendo cátions alumínio e magnésio (Ward, 1984). Sabe-se que as variações estruturais são responsáveis por alterar propriedades físico-químicas das argilas, tais como a carga da superfície, influenciando suas propriedades adsorventes (Ward, 1984).

Neste trabalho, demonstrou-se a compatibilidade da ulvana com os diluentes caulinita e sílica amorfa. A correta seleção do diluente é o passo inicial no preparo de uma formulação PM (Ward, 1984; Medugno, 2007). Sendo assim, faz-se necessário, em trabalhos futuros, a seleção dos demais componentes da formulação, tais como os adjuvantes. Ao término, a formulação ideal deve permitir a maximização do potencial elicitor do polissacarídeo e sua aplicação em menores doses. Por fim, pode-se concluir que a sílica amorfa ou a caulinita mantiveram a eficiência da ulvana em reduzir a antracnose, enquanto que a atapulgita afetou negativamente o desempenho do polissacarídeo.

\section{AGRADECIMENTOS}

Os autores agradecem a Coordenação de Aperfeiçoamento de Pessoal de Nível Superior / REUNI pela concessão de bolsa ao primeiro autor e ao Laboratório 
Eficiência de formulações de ulvana em induzir resistência em Phaseolus vulgaris...

de Caracterização Tecnológica - LTC da Escola Politécnica da Universidade de São Paulo - EPUSP pelas análises de granulometria.

\section{REFERÊNCIAS BIBLIOGRÁFICAS}

Araújo L, Valdebenito-Sanhueza RM, Stadnik MJ (2010) Avaliação de formulações de fosfito de potássio sobre Colletotrichum gloeosporioides in vitro e no controle pós-infeccional da mancha foliar de Glomerella na macieira. Tropical Plant Pathology 35:5459.

Aziz A, Poinssot B, Daire X, Adrian M, Bézier A, Lambert B, Joubert JM, Pugin A (2003) Laminarin elicits defense responses in grapevines and induces protection against Botrytis cinerea and Plasmopara viticola. Molecular Plant-Microbe Interactions 16:1118-1128.

Carroll D, Starkey HC (1971) Reactivity of clay minerals with acids and alkalies. Clay and Clay Minerals 19:321-333.

Cluzet S, Torregrosa C, Jacquet C, Lafitte C, Fournier J, Mercier L, Salamagne S, Briand X, Esquerré-Tugayé MT, Dumas B (2004) Gene expression profiling and protection of Medicago truncatula against a fungal infection in response to an elicitor from green algae Ulva spp. Plant, Cell and Environment 27:917-928.

Elmer PAG, Reglinski T (2006) Biosuppression of Botrytis cinerea in grapes. Plant Pathology 55:155-177.

Knowles A (2008) Recent developments of safer formulations of agrochemicals. Environmentalist 28:35-44.

Laza AL, Jaber M, Miehé-Brendlé J, Demais H, Le Deit H, Delmotte L, Vidal L (2007) Green nanocomposites: synthesis and characterization. Journal of Nanoscience and Nanotechnology 7:1-7.

Loffaguen JC, Talamini V, Stadnik MJ (2005) Identificação da raça 73 de Colletotrichum lindemuthianum, agente causal da antracnose-do-feijoeiro, em dois municípios do Alto Vale do Itajaí, SC. Agropecuária Catarinense 18:87-89.

Medugno C (2007) Roteiro para formulação experimental de pó molhável de biopesticida (sigla internacional WP). In: Valdebenito-
Sanhueza RM, Melo IS (Eds.) Métodos usados no biocontrole de fitopatógenos. Bento Gonçalves RS. Embrapa Uva e Vinho. pp. 109-115.

Murray HH (2007) Applied Clay Mineralogy. Amsterdam. Elsevier Academic Press.

Paulert R, Talamini V, Cassolato JEF, Duarte MER, Noseda MD, Smania Júnior A, Stadnik MJ (2009) Effects of sulfated polysaccharide and alcoholic extracts from Green seaweed Ulva fasciata on anthracnose severity and growth of common bean (Phaseolus vulgaris L.). Journal of Plant Diseases and Protection 116:263-270.

Pradhanang PM, Ji P, Momol MT, Olson SM (2005) Application of acibenzolar-S-methyl enhances host resistance in tomato against Ralstonia solanacearum. Plant Disease 89:989-993.

Rava CA, Molina J, Kauffmann M, Briones I (1993) Determinación de razas fisiológicas de Colletotrichum lindemuthianum en Nicaragua. Fitopatologia Brasileira 18:388-391.

Renard-Merlier D, Randoux B, Nowak E, Farcy F, Durand R, Reignault P (2007) Iodus 40, salicylic acid, heptanoyl salicylic acid and trehalose exhibit different efficacies and defense targets during a wheat/powdery mildew interaction. Phytochemistry 68:1156-1164.

Stadnik MJ, Paulert R (2008) Uso de macroalgas marinhas na agricultura. In: Congresso Brasileiro de Ficologia, Itajaí SC. XI Congresso Brasileiro de Ficologia / Simpósio Latino-americano sobre algas nocivas. Rio de Janeiro RJ. Museu Nacional do Rio de Janeiro 30:267-279.

Talamini V, Souza EA, Pozza EA, Carrijo FRF, Ishikawa FH, Silva KJD, Oliveira FA (2004) Identificação de raças patogênicas de Colletotrichum lindemuthianum a partir de isolados provenientes de regiões produtoras de feijoeiro comum. Summa Phytopathologica 30:371-375.

Walters DR, Paterson L, Walsh DJ, Havis ND (2008) Priming for plant defense in barley provides benefits only under high disease pressure. Physiological and Molecular Plant Pathology 73:95-100.

Ward MG (1984) Formulation of biological insecticides. In: Scher HB (Ed.) Advances in Pesticide Formulation Technology. American Chemical Society. pp. 175-184.

Wordell Filho J, Stadnik MJ (2008) Controle integrado da antracnose no feijoeiro. Agropecuária Catarinense 21:56-59. 